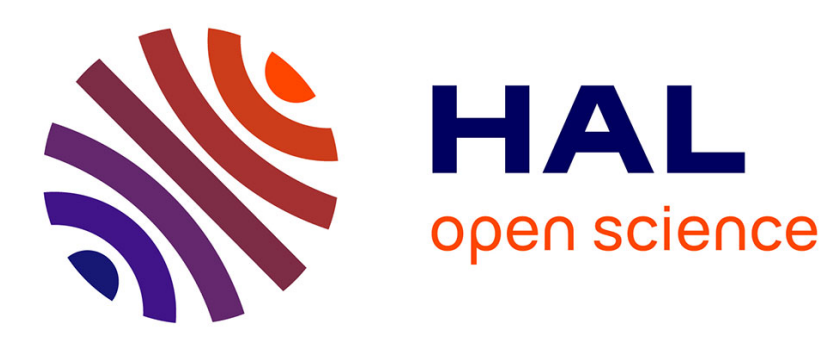

\title{
First detection of CYP1A1 and CYP2B induction in Mediterranean cetacean skin biopsies and cultured fibroblasts by western blot analysis
}

\author{
Maria Cristina Fossi, Letizia Marsili, Silvia Casini, Daniela Bucalossi
}

\section{- To cite this version:}

Maria Cristina Fossi, Letizia Marsili, Silvia Casini, Daniela Bucalossi. First detection of CYP1A1 and CYP2B induction in Mediterranean cetacean skin biopsies and cultured fibroblasts by western blot analysis. Marine Environmental Research, 2008, 66 (1), pp.3. 10.1016/j.marenvres.2008.02.006 . hal-00501939

\section{HAL Id: hal-00501939 \\ https://hal.science/hal-00501939}

Submitted on 13 Jul 2010

HAL is a multi-disciplinary open access archive for the deposit and dissemination of scientific research documents, whether they are published or not. The documents may come from teaching and research institutions in France or abroad, or from public or private research centers.
L'archive ouverte pluridisciplinaire HAL, est destinée au dépôt et à la diffusion de documents scientifiques de niveau recherche, publiés ou non, émanant des établissements d'enseignement et de recherche français ou étrangers, des laboratoires publics ou privés. 


\section{Accepted Manuscript}

First detection of CYP1A1 and CYP2B induction in Mediterranean cetacean skin biopsies and cultured fibroblasts by western blot analysis

Maria Cristina Fossi, Letizia Marsili, Silvia Casini, Daniela Bucalossi

PII:

S0141-1136(08)00022-6

DOI:

10.1016/j.marenvres.2008.02.006

Reference:

MERE 3174

To appear in:

Marine Environmental Research

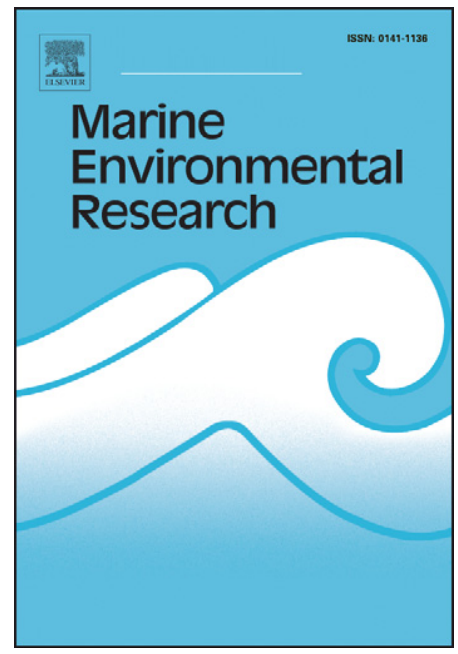

Please cite this article as: Fossi, M.C., Marsili, L., Casini, S., Bucalossi, D., First detection of CYP1A1 and CYP2B induction in Mediterranean cetacean skin biopsies and cultured fibroblasts by western blot analysis, Marine Environmental Research (2008), doi: 10.1016/j.marenvres.2008.02.006

This is a PDF file of an unedited manuscript that has been accepted for publication. As a service to our customers we are providing this early version of the manuscript. The manuscript will undergo copyediting, typesetting, and review of the resulting proof before it is published in its final form. Please note that during the production process errors may be discovered which could affect the content, and all legal disclaimers that apply to the journal pertain. 


\title{
First detection of CYP1A1 and CYP2B induction in
}

\section{Mediterranean cetacean skin biopsies and cultured fibroblasts by \\ western blot analysis}

\author{
Maria Cristina Fossi *, Letizia Marsili, Silvia Casini, Daniela Bucalossi \\ Department of Environmental Sciences, Siena University, Via Mattioli 4, 53100 Siena, Italy.
}

\begin{abstract}
The need to develop powerful tools to detect exposure and effects of POPs and emerging contaminants in Mediterranean cetaceans led us to develop a suite of sensitive nonlethal biomarkers in integument biopsies of free-ranging animals. In order to propose induction of CYP1A1 and CYP2B, detected by western blot analysis, as biomarkers of exposure to OCs, PAHs and PBDEs, a three-phase experimental protocol (in vitro experiments, calibration experiments and field applications) was followed using fibroblast cell cultures and biopsies of Mediterranean Stenella coeruleoalba and Tursiops truncatus. This methodology was confirmed to be sensitive and stable in comparison to previous methods used to detect CYP1A1 in biopsies, enabling analysis of several inducible proteins in nonlethal samples and analysis of material from stranded animals.
\end{abstract}

Keywords: Mediterranean cetaceans; Integument biopsy; Fibroblast cell cultures; CYP1A1; CYP2B; Western blot; OCs; PBDEs

*Corresponding author: fossi@ unisi.it (M.C. Fossi) 
In the last 20 years, there has been growing concern about the potential risk to Mediterranean cetaceans of high bioaccumulation of organochlorines (OCs) (Fossi et al,, 1992; Fossi et al., 2003a) and emerging contaminants, such as polybrominated diphenyl ethers (PBDEs) (Alaee et al., 2003; Fossi et al., 2006). While levels of organochlorine compounds are decreasing, concentrations of PBDEs seem to be increasing in the Mediterranean environment.

Several international institutions (IWC, ACCOBAMS) have encouraged research and development of sensitive non-lethal biomarkers in biopsies of free-ranging animals, to define the toxicological status of cetaceans. The objective of our lab was to develop a "multi-trial biomarker tool" applied to cetacean integument biopsies to detect "toxicological stress syndromes". We used a multidisciplinary approach, merging genomic and proteomic studies (Western blot, RT-PCR, cultured fibroblasts) with analysis of POPs, PAHs and PBDEs, and genetic population studies. Here, we summarize the main results of part of this project, focusing on detection of CYP1A1 and CYP2B induction in cetacean biopsies and cultured fibroblasts by Western blot (WB) analysis, as biomarkers of exposure to OCs, PAHs and PBDEs.

In order to validate this methodology, a three phase experimental protocol was followed. In the first phase (in vitro experiments), we used WB to detect CYP1A1 and CYP2B induction caused by exposure of cultured fibroblasts of Stenella coeruleoalba and Tursiops truncatus to PBDEs and OCs. In the second phase (calibration experiments), we validated WB analysis of CYP1A1 and CYP2B as a semi-quantitative detection tool using calibration curves of CYP450 obtained from liver and skin of stranded specimens of Tursiops truncatus. Finally in the third phase (field applications), we applied WB analysis of CYP1A1- 
CYP2B as a semi-quantitative tool to explore differences in exposure to OCs, PAHs and PBDEs of three sub-populations of Stenella coeruleoalba.

Sub-samples of skin and liver of stranded Tursiops truncatus $(\mathrm{n}=2)$ were obtained 4-8 hours after death. Integument biopsies (Fossi et al, 2003a) were obtained from free-ranging Stenella coeruleoalba $(\mathrm{n}=60)$ from the Mediterranean Whale Sanctuary, Ionian Sea and Strait of Gibraltar.

Gender was determined genetically according to Berube and Palsboll (1996). Fibroblasts were cultured from biopsies according to Marsili et al. (2000) and were subject to two different experimental protocols for $48 \mathrm{~h}$, using two classes of CYP-inducers (Fossi et al., 2006). Firstly, a mixture of Arochlor 1260, pp'DDT and pp'DDE in DMSO were used at three concentrations: 1,5 and $25 \mu \mathrm{g} / \mathrm{ml}$, plus DMSO (0.05\%) as control. Secondly, a mixture containing 27 PBDEs in nonane were used at three concentrations: $0.1,0.05$ and $0.01 \mu \mathrm{g} / \mathrm{ml}$, plus nonane $(0.01 \mu \mathrm{g} / \mathrm{ml})$ as control.

Homogeneous sub-samples of biopsies (including epidermis, dermis and blubber layers; Angell et al., 2004) were homogenized in aryl-hydrocarbon-receptor (AhR) buffer (Wilson et al., 2007) in a Tissue Lyser (Qiagen). The homogenate was centrifuged twice and the supernatant (S9) was analyzed for total proteins and then by WB.

For WB analysis, S9 tissue homogenates (in duplicate) and fibroblast extracts were separated by SDS-PAGE (10\% polyacrylamide gels) and blotted onto nitrocellulose; the membranes were saturated with blocking solution for $1 \mathrm{~h}$. Primary polyclonal antibodies were from Oxford Biochemical Research. Goat anti rabbit CYP1A1 and anti CYP2B4, diluted 1:5000 and 1:1000, respectively, in TTBS-1\% gelatin, were incubated with cetacean proteins overnight. Incubation with anti-goat HRP-labelled secondary antibody (1:3000) was performed (1h) and detected according to the BioRad Immun-Star-HRP-ChemiluminescentKit booklet. 
In order to validate $\mathrm{WB}$ analysis of $\mathrm{CYP} 1 \mathrm{~A} 1$ and $\mathrm{CYP} 2 \mathrm{~B}$ as a semi-quantitative detection tool in biopsies, a series of calibration curves of CYP450 from liver (ranging from 1.2 to 4.8 pmol of CYP450) and skin (from 0.095 to $2.400 \mathrm{pmol}$ ) of stranded Tursiops truncatus were analysed in triplicate. A triplicate skin standard (SS) was analyzed within the curves and maintained as internal standard in subsequent WBs. Semi-quantitative analysis was performed for each WB with Quantity-One software (BioRad) using Adjusted Volume $\left(\right.$ Intensity $\left.* \mathrm{~mm}^{2}\right)$ as quantitative parameter. The data was correlated with increasing pmol of CYP450 and two Excel Macros (one for CYP1A1 and one for CYP2B) were produced incorporating the normalizing factor of SS for quantification of unknown biopsy samples. The calibration curves were validated for semi-quantitative analysis of CYP1A1 and CYP2B in three different populations of striped dolphin.

In the first phase (in vitro experiments), we applied the WB technique to detect CYP1A1 and CYP2B induction produced by PBDEs and OCs in fibroblasts of the two species of dolphins (Fossi et al., 2006). Increasing induction was detected in both species with increasing concentrations of contaminants. In female striped dolphin cells, CYP2B increased 3-, 15- and 16-fold with respect to control, with increasing concentrations of OCs. The highest trend of induction (CYP2B) was found in Tursiops truncatus cells treated with PBDEs. In the second phase (calibration experiments), we validated WB analysis of CYP1A1 (Fig. 1A) and CYP2B (Fig. 1B) as a semi-quantitative detection tool with the calibration curves of CYP450 obtained from liver and skin of stranded specimens of Tursiops truncatus. A linear correlation was found between relative pmol CYP1A1 and Adjusted Volume (Int. $\left.* \mathrm{~mm}^{2}\right)(\mathrm{R}=0.99)$ and between relative pmol CYP2B and Adjusted Volume $(\mathrm{R}=0.99)$. The two Excel Macros (CYP1A1 and CYP2B), incorporating the normalizing factor of SS (Skin Standard) (Fig 1A and 1B) will be used for quantification of unknown biopsy samples (third phase). In the third phase (field applications), we applied the WB analysis of CYP1A1 and 
CYP2B as semi-quantitative detection tools, in biopsy samples, to explore different exposure to planar (polycyclic aromatic hydrocarbons and planar halogenated aromatic hydrocarbons) (Angell et al., 2004; Godard et al., 2004; Wilson et al., 2007) and globular (globular halogenated aromatic hydrocarbons) lipophilic contaminants, respectively, in three subpopulations of Mediterranean Stenella coeruleoalba. Here the calibration curves were validated (as pilot experiment) for semi-quantitative analysies of CYP1A1 (Fig. 2) and CYP2B in male sub-samples collected in the three areas. Future studies will concern correlations between CYP1A1/CYP2B and blubber levels of contaminants.

In conclusion this methodology applied to skin biopsies and stranded cetaceans was confirmed to be sensitive and stable in comparison to previous methods used to detect CYP1A1 in biopsies (enzymatic (Fossi et al., 1992; Fossi et al., 2003a) and immunohistochemistry techniques), enabling analysis of several inducible proteins in nonlethal samples and material from stranded animals. Future development of more sensitive techniques (RT-PCR and proteomics) with chemical data (OCs, PBDEs, PAHs) will provide more complete information about cetacean toxicological stress syndromes.

\section{Acknowledgements}

We thank Dr. Mori, Dr. Porcelloni, Dr. Caliani, Dr. Spinsanti, Dr. Jimenez, Dr. Gaspari, Dr. Panigada and Dr. De Stephanies for technical support in the sampling and laboratory activities. This project was supported by the Italian Ministry for Environment.

\section{References}

Angell, C.M., Wilson, J.Y., Moore, M.J., and Stegeman, J.J. (2004). Marine Mammalian Sciences, 20, 554-566. 
Alaee, M., Arias, P., Sjödin, A., and Bergman, A. (2003). Environmental International, 29, 683-689.

Berube, M., and Palsboll, P. (1996). Molecular Ecology, 5, 283-287.

Fossi, M.C., Marsili, L., Leonzio, C., Notabartolo di Sciara, G., Zanardelli, M., and Focardi S. (1992). Marine Pollution Bulletin, 24, 459-461.

Fossi, M.C., Marsili, L., Neri, G., Natoli, A., Politi, E., and Panigada, S. (2003a). Marine Pollution Bulletin, 46, 972-982.

Fossi, M.C., and Marsili, L. (2003b). Pure Applied Chemistry, 75, 2235-2247.

Fossi, M.C., Marsili, Casini, S., and Bucalossi D. (2006). Marine Environmental Research, 62, 200-2004.

Godard, C.A.J., Smolowitz, R.M., Wilson, J.Y., Payne, R.S., and Stegeman, J.J. (2004). Toxicological Sciences, 80, 268-275.

Marsili, L., Fossi, M.C., Neri, G., Casini, S., Gardi, C., Palmeri, S., et al. (2000). Marine Environmental Research, 50, 649-652.

Wilson J.Y., Wells, R., Aguilar, A., Borrel, A., Tornero, V., Reijnerds, P., et al (2007). Toxicological Sciences (on- line). 


\section{Figure Captions}

Fig. 1. Western blot analysis (WB) of CYP1A1 (A) and CYP2B (B) calibration curves of CYP450 from skin (ranging from 0.095 to 2.400 pmol of CYP450) of stranded specimens of Tursiops truncatus. A triplicate skin standard (SS) was analyzed within the calibration curve, and maintained as internal standard in subsequent WBs. Semi-quantitative analysis was performed for each WB (in triplicate) with Quantity One software (BioRad, 1-D Analysis Software) using Adjusted Volume (Intensity $* \mathrm{~mm}^{2}$ ) as quantitative parameter.

Fig. 2. Western blot (WB) analysis of CYP1A1 in male specimens of three sub-populations of Mediterranean Stenella coeruleoalba (biopsy samples). Different steps of the field validation of the methodology (WB, Quantity one analysies, Excel Macros and Relative pmol CYP1A1) are reported. The results are express as Relative pmol CYP/mg prot. 


\section{ACCEPTED MANUSCRIPT}

Figure 1a

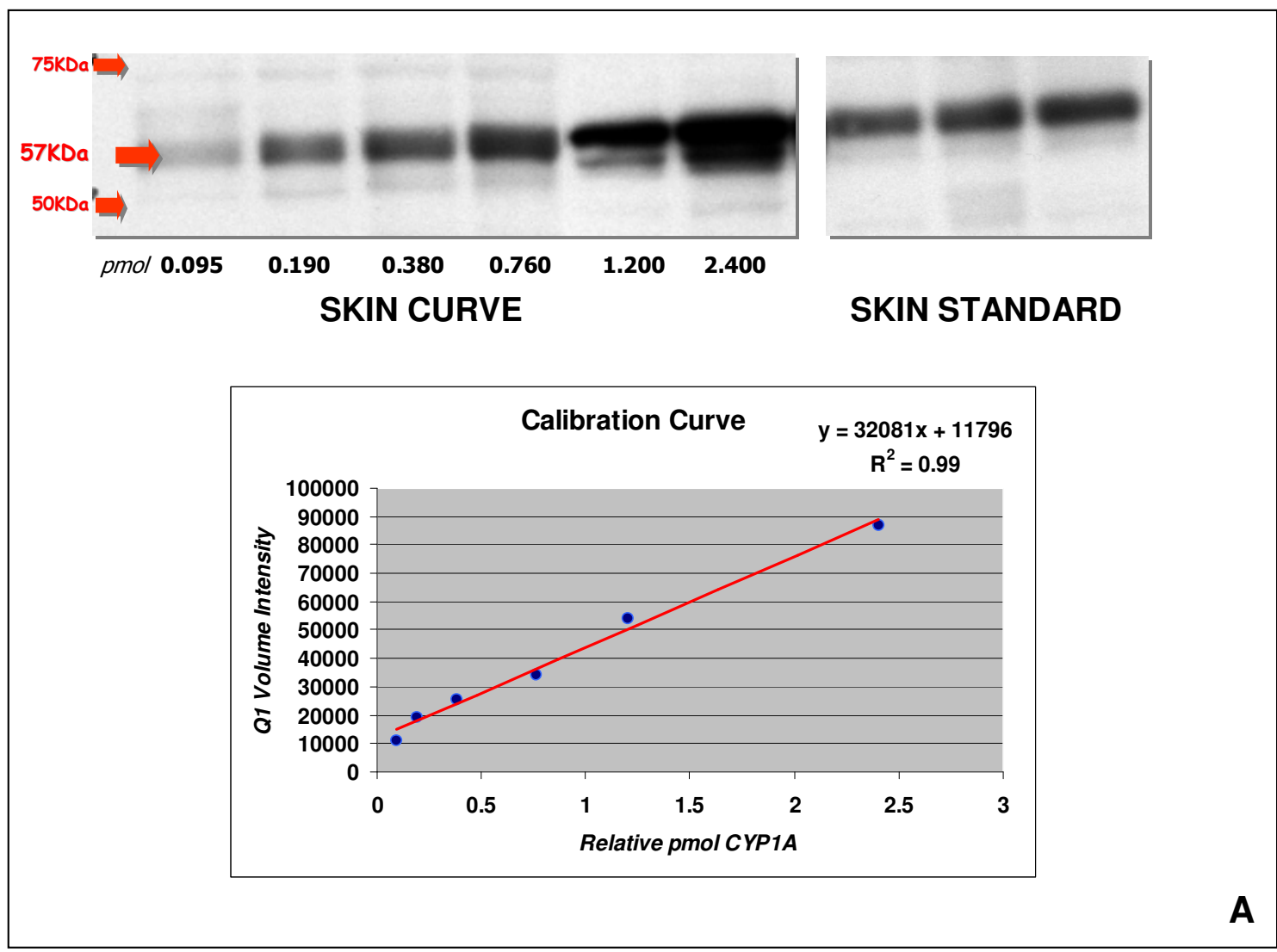


Figure 1b

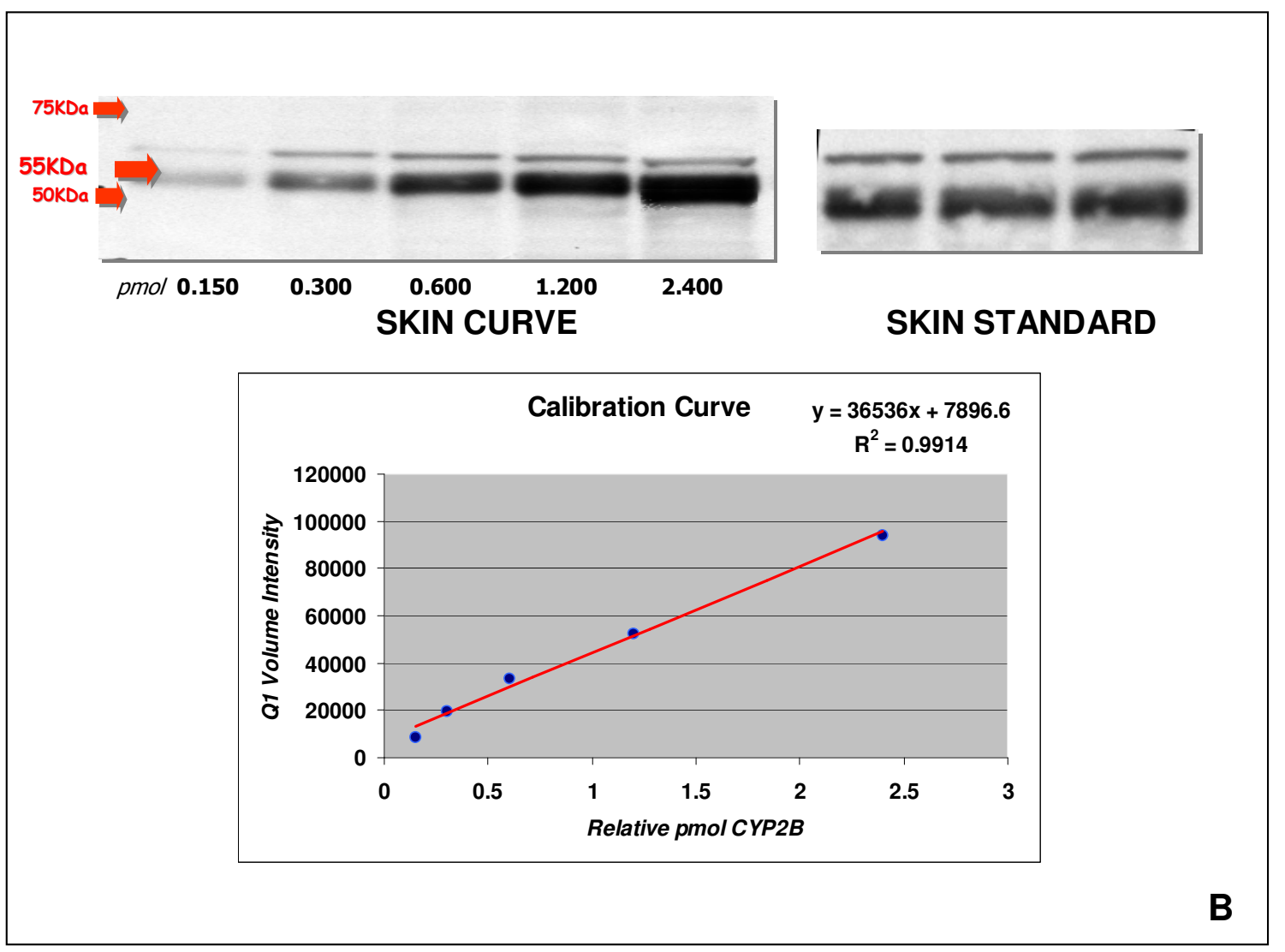


Figure 2

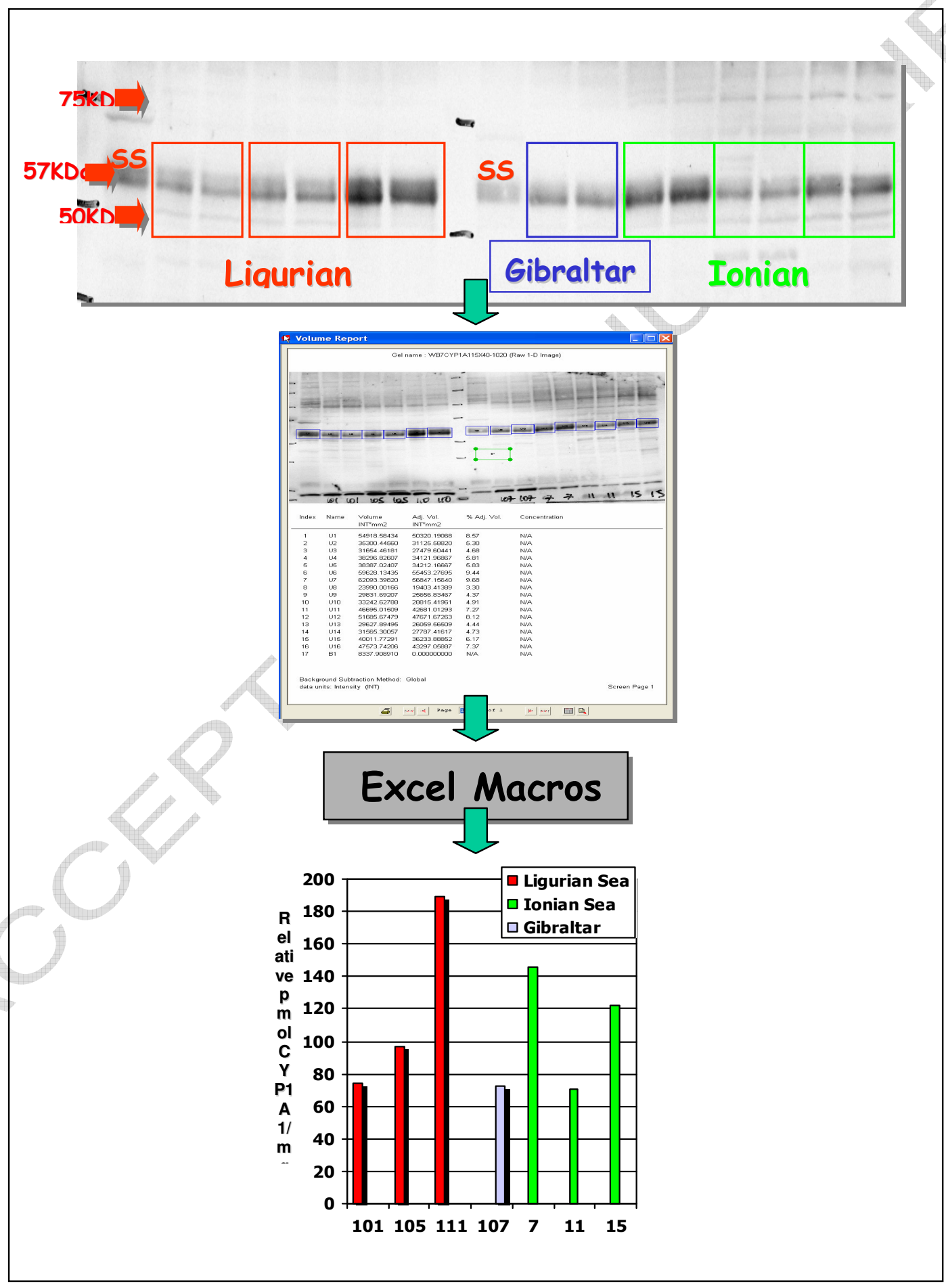

